\title{
Comparison of Approaches to Select a Propensity Score Matched Control Group in the Absence of an Obvious Start of Follow Up for this Group: An Example Study on the Economic Impact of the DMP Bronchial Asthma
}

\author{
Vergleich von Methoden zur Selektion einer Propensity Score \\ gematchten Kontrollgruppe in Abwesenheit eines Beginns des \\ Follow-ups: Eine Studie zum ökonomischen Nutzen des DMP \\ Asthma bronchiale
}

\section{(ㄷ) (i) (우) $\Theta$}

Authors

Josephine Jacob, Niklas Schmedt, Lennart Hickstein, Wolfgang Galetzka, Jochen Walker, Dirk Enders

\author{
Affiliation \\ InGef - Institut für angewandte Gesundheitsforschung \\ Berlin GmbH, Berlin
}

\section{Key words}

Propensity Score Matching, claims data, disease management program, health care costs, mortality, start of follow-up

\section{Schlüsselwörter}

Beginn Follow-up, Propensity Score Matching, Sekundärdaten, Disease Management Programm, Leistungskosten, Mortalität

\section{Bibliography}

DOI https://doi.org/10.1055/a-0948-5356

Online-Publikation: 23.10.2019

Gesundheitswesen 2020; 82 (Suppl. 2): S151-S157

(c) Georg Thieme Verlag KG Stuttgart · New York

ISSN 0949-7013

\section{Correspondence}

Josephine Jacob

InGef - Institut für angewandte Gesundheitsforschung

Berlin $\mathrm{GmbH}$

Spittelmarkt 12

10117 Berlin

josephine.jacob@ingef.de

Supplementary Material Table S1-S3 und Fig. S1 finden Sie online unter https://doi.org/10.1055/a-0948-5356 the date of enrollment into the new service is an obvious start of follow-up for participants, the strategy to select potential controls is not straightforward due to a missing start of followup to ascertain possible confounders. The aim of this study was to compare different approaches to select controls via Propensity Score Matching (PSM) using the disease management program (DMP) bronchial asthma (BA) as an example.

Methods We conducted a retrospective cohort study of BA patients between 2013 and 2016 to examine total one-year health care costs and all-cause mortality. We implemented different scenarios regarding the selection of potential controls: I) allotment of a random index date with subsequent PSM, II) calendar year-based PSM (landmark analysis) and III) calendar quarter-based PSM. In scenario I, we applied 2 approaches to assign a random index date: a) assign random index date among all quarters with a BA diagnosis and $b$ ) assign random index date and thereafter examine if a BA diagnosis was documented in that quarter.

Results No significant differences in total one-year health care costs between DMP BA participants and non-participants were observed in any of the scenarios. This could to some extent be explained by the higher mortality in the control groups in all scenarios.

Conclusion If the loss of potential controls can be compensated, scenario Ib is a pragmatic option to select a control group. If that is not the case, scenario III is the more sophisticated approach, with the limitation that baseline characteristics prior PSM cannot be depicted and computational time or memory size needed to conduct the analysis need to be sufficient.

\section{ZUSAMMENFASSUNG}

Hintergrund Routinedaten gesetzlicher Krankenkassen werden häufig zur Evaluation ökonomischer Effekte neuer Ver- 
sorgungsformen genutzt. Während als Beginn des Follow Ups für Teilnehmer häufig der Tag der Einschreibung in das Programm genutzt werden kann, ist die Selektion von Kontrollen schwieriger aufgrund des Fehlens eines solchen Ereignisses. Ziel dieser Studie war es, Vorteile und Limitationen von 3 Methoden zur Selektion von Kontrollen mittels Propensity Score Matching (PSM) am Fallbeispiel des Disease Management Programms (DMP) Asthma bronchiale zu zeigen.

Methoden Eine retrospektive Kohorte bestehend aus Asthma Patienten zwischen 2013 und 2016 wurde identifiziert um Unterschiede in den Gesamtleistungskosten und Gesamtmortalität zu betrachten. Wir haben 3 Szenarien zur Auswahl geeigneter Kontrollen verglichen: I) Zuteilung eines zufälligen Indexdatums mit anschließendem PSM, II) Kalenderjahr basiertes PSM (Landmark Analyse) und III) Kalenderquartal basiertes PSM. Im ersten Szenario wurden 2 Methoden zur Zuteilung eines zufälligen In- dexdatums umgesetzt: a) Zuteilung eines zufälligen Indexdatums zu einem Quartal mit Asthma Diagnose und b) Zuteilung eines zufälligen Indexdatums und anschließende Überprüfung ob in dem selektierten Quartal eine Asthmadiagnose vorlag.

Ergebnisse In keinem der Szenarien wurden signifikante Unterschiede in den Gesamtleistungskosten zwischen DMP Teilnehmern und Nicht-Teilnehmern beobachtet, was möglicherweise durch Mortalitätsunterschiede zwischen den Gruppen erklärt werden kann.

Fazit Im Falle einer ausreichend großen Anzahl potentieller Kontrollen ist Szenario Ib eine pragmatische Option zur Selektion einer Kontrollgruppe. Andernfalls stellt Szenario III die ausgereiftere Methode dar, obwohl keine Baseline-Charakteristika vor PSM dargestellt werden können und ausreichend Rechenkapazität bereitgestellt werden muss.

\section{Introduction}

Cohort studies are often used to compare participants of a new service to non-participants. In these studies, participants are typically followed from the start of the service until the occurrence of the outcome event or the end of a prespecified follow up period. These studies must cope with 2 challenges: i) to avoid selection bias, participants should be followed from start of the service (start of follow up) and ii) potential controls should be selected from the population who is comparable with respect to possible confounders. While i) can be easily implemented, ii) is not straightforward due to a missing start of follow up to ascertain possible confounders. For the assessment of the economic effectiveness of new health services it is essential to select appropriate methods for the selection of controls. The aim of this study was to compare 3 approaches to select propensity score matched controls in the absence of an obvious start of follow up for non-participants using the disease management program (DMP) DMP bronchial asthma (BA) as an example. As the primary outcome total one-year health care costs were compared between patients who newly enrolled in DMP bronchial asthma between 2013 and 2016 and patients who did not.

\section{Methods}

\section{Data source}

Claims data are a valuable data source for health services research to investigate the economic impact of new health care services [1-4].

The study was based on anonymized claims data from the InGef (Institut für angewandte Gesundheitsforschung Berlin) research database $^{1}[5,6]$. At the time of analysis, the database contained longitudinal data of approximately 8.3 million Germans insured in one of 61 statutory health insurances (SHI) between 2012 and 2017. In addition to sociodemographic information, the database contains information about ambulatory services and diagnoses; hospital data including admission periods, main and secondary dis-

1 former HRI research database charge diagnoses (coded according to the German modification of the $10^{\text {th }}$ revision of the International Classification of Diseases (ICD$10 \mathrm{GM})$ ) and procedures conducted; drug prescription data; information on prescribed aids and remedies; and the costs which accrued in these sectors. All patient-level and provider-level data in the InGef research database are anonymized to comply with German data protection regulations and German federal law. Hence, approval of an Ethics Committee was not required.

\section{Study cohort}

We conducted a retrospective cohort study including BA patients between 2013 and 2016. Data from 2012 to 2017 were used to assess in- and exclusion criteria, baseline characteristics, total oneyear health care costs and one-year all-cause mortality in follow up.

Patients were eligible to enter the cohort if they were continuously enrolled in 2012. Furthermore, patients had to be continuously enrolled between 2013 and 2017 or between 2013 and their date of death (cf. - Fig. 1). Patients had to have at least one verified ambulatory BA diagnosis (ICD-10 GM J45) between 2013 and 2016. Individuals enrolled in the DMP BA before 2013 were excluded from the study population. Three different scenarios to determine participants and non-participants with corresponding baseline period and follow up were defined. In each of the scenarios, patients with extreme total health care costs of more than $100,000 €$ in the baseline period were excluded. All patients had to be alive on the first day of follow up.

\section{Analysis scenarios/observation periods}

Scenario la - random index date among quarters with BA diagnosis

Enrollment in the DMP BA was assessed between 2013 and 2016. Participants were followed from the first day of the quarter following the index quarter of enrollment for a period of one year or until death. Non-participants were assigned a random index date based on the distribution of DMP enrollment dates among participants and were followed from the first day of the quarter after the random index date. Random index dates were only assigned to quarters 


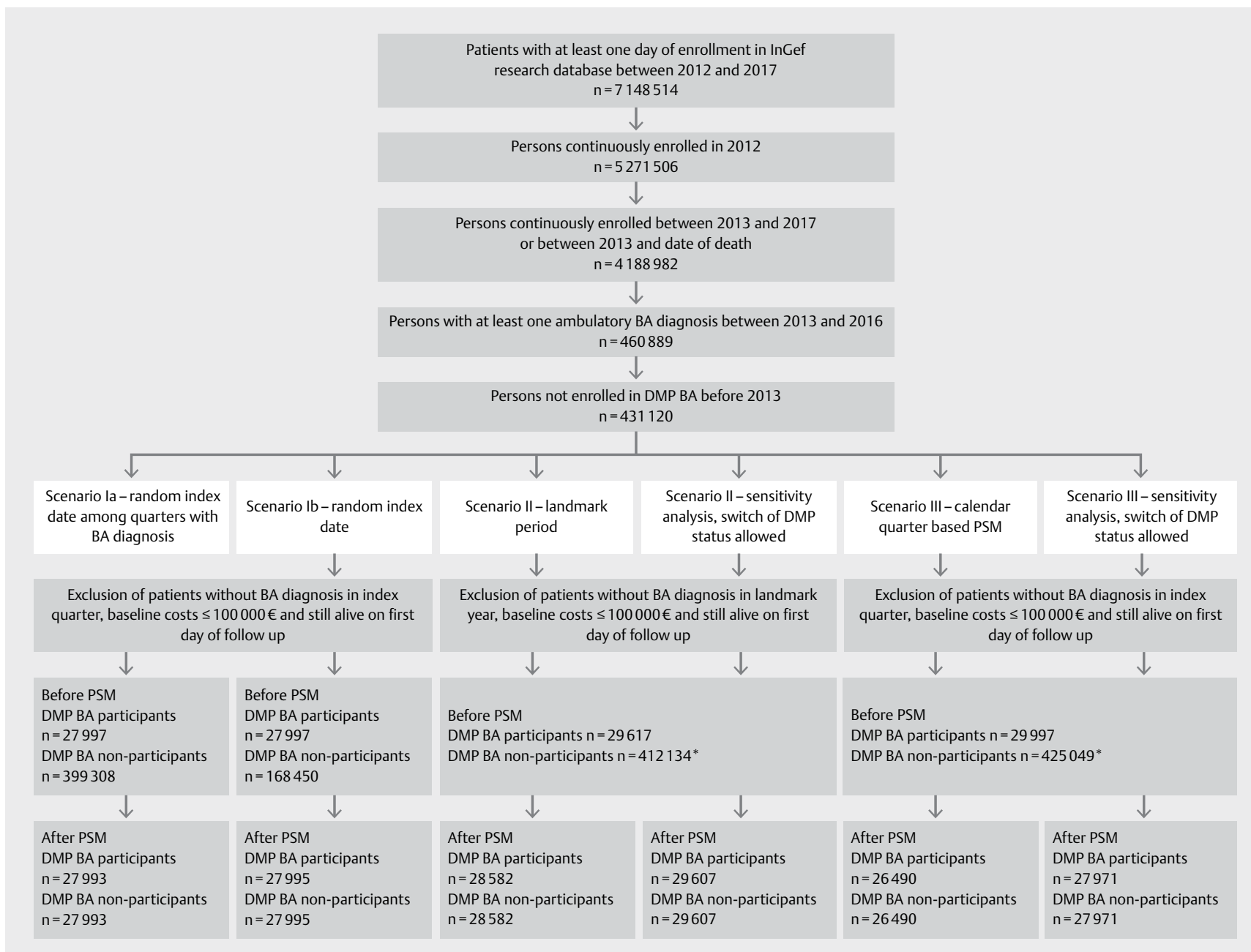

*DMP BA non-participants could become participants later on; DMP Disease Management Program; BA bronchial asthma; PSM Propensity Score Matching

- Fig. 1 Flow chart depicting selection of DMP BA participants and DMP BA non-participants by analysis scenarios.

in which an ambulatory verified BA diagnosis was documented. Covariates were assessed in the baseline period of four quarters before the index quarter.

\section{Scenario lb - random index date}

This scenario is similar to scenario la with the exception that the assignment of random index dates was not restricted to quarters with a BA diagnoses. Patients without a verified BA diagnosis in the quarter of the assigned index date and patients who had died before the assigned random index date were excluded from the analysis.

\section{Scenario II - landmark period}

DMP enrollment was assessed in each year between 2013 and 2016. Patients were classified into 2 exposure groups depending on whether they enrolled in the DMP BA between January $1^{\text {st }}$ and December $31^{\text {st }}$ of the respective year (landmark year). Follow up started on January $1^{\text {st }}$ of the following year for both participants and non-participants and ended on the last day of that year or the day of death. Covariates were assessed in the year prior to the landmark year. Participants and non-participants who were matched in one year were excluded from the matching procedure in the subsequent years. Selected participants and non-participants in each year were pooled and analyzed as one cohort.

\section{Scenario III - calendar quarter based PSM}

In every calendar quarter between 2013 and 2016 individuals who enrolled in the DMP BA were matched to individuals who did not enroll in the DMP BA based on covariates assessed in the 4 quarters prior to that calendar quarter. Participants and non-participants which were matched in one calendar quarter were excluded from the matching procedure in the quarters thereafter. This process was repeated for all calendar quarters between 2013 and 2016. Individuals were followed from the first day following the matching quarter for a period of four quarters or until death.

In addition, we conducted pre-specified sensitivity analysis for scenario II and III in which patients could be selected as a control first and later switch into the DMP group. Follow up for individuals who were selected as a control first and later became a case was not censored at the time of switch. 


\section{Baseline characteristics}

Baseline characteristics were included in the calculation of the Propensity Score (PS) to adjust for possible confounders regarding the investigated outcome between the study groups. ( $>$ Table S1) in the supplement provides an overview of all baseline characteristics assessed and their definition.

\section{Exposure and endpoints}

The exposure DMP BA enrollment was assessed using the DMP information available in the InGef research database.

The sum of all-cause cumulated costs in $€$ for hospitalizations, ambulatory care, drug treatment and remedies and aids within the one-year follow up period was investigated as the primary outcome in this study.

To assess the potential impact of the proportion of deceased individuals on the primary outcome in each study group, the oneyear all-cause mortality was investigated.

\section{Statistical analysis}

Baseline characteristics are reported for the unmatched (scenarios la and Ib only) and matched BA cohorts. Baseline characteristics for the unmatched cohorts of scenarios II and III and the respective sensitivity analyses are not presented because patients could be potential controls in multiple years (scenario II) or quarters (scenario III) and unique baseline periods could not be determined.

A Propensity Score Matching (PSM) was performed to select matched study cohorts in all scenarios [7-9]. PSM is a method which attempts to match DMP BA participants and non-partici- pants based on their probability for participation in the DMP. This probability was calculated using a logistic regression model with the variable DMP BA participation as the dependent variable. The covariates which were included in the calculation of the Propensity Score (PS) are listed in $\triangleright$ Table $\mathbf{S 1}$ of the supplement. Based on the PS, a 1:1 nearest-neighbor matching with a caliper of 0.2 of the standard deviation of the logit of the propensity score was conducted.

The balance of covariates in the baseline period between the study groups were assessed by calculating the standardized difference in means (SMD), using a threshold of 0.1 to indicate imbalance [10]. The outcome total one-year health care costs and oneyear all-cause mortality were compared using a paired t-test and McNemar's test, respectively, to account for the matched structure of the data [11].

Analyses were performed using $R$ version 3.5.0. The PS matching was performed with the R package Matchlt (version 3.0.2).

\section{Results}

A total of 431,120 BA patients were selected from the InGef research database between 2013 and 2016. Approximately $7 \%$ of these patients enrolled in the DMP BA in this period (cf. - Fig. 1).

- Table 1 displays patient characteristics of the unmatched DMP BA participants and DMP BA non-participants in scenario la and lb. DMP BA participants were younger, more commonly visited a pulmonologist and received more BA specific drugs, such as shortacting beta agonists and inhaled corticosteroids, than BA patients

- Table 1 Baseline characteristics of the unmatched study groups in scenario la and lb in the four quarters before the index date.

\begin{tabular}{|c|c|c|c|c|c|}
\hline \multirow[t]{2}{*}{ Characteristic } & \multirow[t]{2}{*}{ DMP $n=27,997$} & \multicolumn{2}{|c|}{ Scenario la } & \multicolumn{2}{|c|}{ Scenario lb } \\
\hline & & Non-DMP $n=399,308$ & SMD & Non-DMP $n=168,450$ & SMD \\
\hline \multicolumn{6}{|l|}{ Demographics } \\
\hline Age [mean (SD)] & $41.0(21.0)$ & $42.8(22.2)$ & -0.08 & $45.9(21.8)$ & -0.22 \\
\hline Female (\%) & 56.5 & 52.3 & -0.08 & 53.5 & -0.06 \\
\hline \multicolumn{6}{|l|}{ Clinical characteristics } \\
\hline Allergy (\%) & 37.4 & 28.0 & 0.21 & 32.2 & 0.11 \\
\hline Influenca vaccination (\%) & 22.0 & 16.6 & 0.14 & 20.8 & 0.03 \\
\hline Charlson Comorbidity Index [mean (SD)] & $1.3(1.1)$ & $1.4(1.6)$ & -0.04 & $1.7(1.6)$ & -0.25 \\
\hline Status asthmaticus (\%) & 0.8 & 0.2 & 0.12 & 0.3 & 0.08 \\
\hline $\begin{array}{l}\mathrm{N} \text { prescriptions short acting beta agonists } \\
\text { [mean (SD)] }\end{array}$ & $2.6(3.0)$ & $1.3(2.6)$ & 0.48 & $1.9(3.1)$ & 0.24 \\
\hline $\begin{array}{l}N \text { prescriptions inhaled corticosteroids [mean } \\
\text { (SD)] }\end{array}$ & $0.8(1.5)$ & $0.4(1.2)$ & 0.27 & $0.5(1.4)$ & 0.16 \\
\hline Enrolled in an additional DMP (\%) & 2.7 & 7.4 & -0.18 & 9.2 & -0.24 \\
\hline \multicolumn{6}{|l|}{ Health care resource utilization } \\
\hline $\mathrm{N}$ visits pulmonologist [mean (SD)] & $0.7(1.2)$ & $0.3(0.87)$ & 0.45 & $0.4(1.0)$ & 0.29 \\
\hline N hospitalizations [mean (SD)] & $0.2(0.6)$ & $0.3(0.8)$ & -0.04 & $0.3(0.8)$ & -0.07 \\
\hline Ambulatory care costs in $€$ [mean (SD)] & $774(738)$ & $650(739)$ & 0.17 & $719(748)$ & 0.07 \\
\hline Hospital costs in $€[$ mean (SD)] & $685(2600)$ & $858(3357)$ & -0.05 & $949(3477)$ & -0.08 \\
\hline Pharmaceutical costs in $€$ [mean (SD)] & $546(1571)$ & $544(1870)$ & 0.00 & $674(2020)$ & -0.07 \\
\hline Costs for aids and remedies in $€$ [mean (SD)] & $180(591)$ & $210(854)$ & -0.04 & $240(892)$ & -0.07 \\
\hline Total treatment costs in $€$ [mean (SD)] & 2184 (3645) & $2262(4683)$ & -0.02 & $2582(4880)$ & -0.08 \\
\hline
\end{tabular}


not enrolled in the DMP BA. The share of patients enrolled in an additional DMP was higher in BA non-participants. Total treatment costs $(€)$ in the baseline period were comparable between DMP BA participants and DMP BA non-participants.

Following the PSM, baseline demographics and clinical characteristics were balanced with all standardized differences smaller than 0.1 in all scenarios (cf. - Table 2). The proportion of DMP BA participants for whom an adequate matching partner could be found was above $95 \%$ in all scenarios except scenario III (88\%, cf. - Fig. 1). Due to the different base cohorts of whom the participants and non-participants are selected, the total number of matched pairs differed substantially between the scenarios: In the sensitivity analysis for scenario II, the largest number of matched pairs $(n=29,607)$ could be analyzed. Scenario III lead to the least matched pairs $(n=26,490)$ after matching.

No significant differences in total health care costs between DMP BA participants and DMP BA non-participants were observed in any one of the scenarios (cf. > Table 3 ). Total health care costs varied, depending on the scenario, between $2636 €$ and $2659 €$ in DMP BA participants and between $2563 €$ and $2634 €$ in DMP BA non-participants. The largest difference between the two patient groups of approximately $90 €$ was observed in the calendar quarter based PSM.

In all scenarios, DMP BA non-participants had a higher mortality than participants (cf. > Table 3). The magnitude of the difference varied greatly between the scenarios. The mortality was more than 3 times higher in scenario la in DMP BA non-participants than in DMP BA participants (0.99 vs. $0.31 \%$; $<<0.001)$. In the landmark approach in scenario II the mortality was still twice as high in DMP BA non-participants than in DMP BA participants. The smallest difference in mortality was found in scenario III.

\section{Discussion}

We investigated 3 different scenarios to select a propensity score matched control group in the absence of an obvious start of follow up in the control group. In summary, total health care costs in the first year after enrollment were similar between BA patients participating in the DMP BA und BA patients who do not in all scenarios. We observed differences regarding the one-year mortality between the 2 patient groups and between the different scenarios.

The similar health care costs between DMP BA participants and non-participants are contradictory to studies evaluating other DMPs, which partly observed significantly reduced costs for participants of the DMP [12]. We attribute this to the fact that DMPs are mostly evaluated regarding inpatient cost or investigated for longer follow up periods $[12,13]$. In our study, in line with other studies investigating the effects of the DMP diabetes mellitus type II, we also observed lower costs in the inpatient setting for DMP BA participants (cf. ( Table S2) in the supplement) $[12,13]$. This was compensated by higher costs in the ambulatory setting (prescriptions and physician visits).

The small difference in health care costs between participants and non-participants is to some extent influenced by the higher mortality in the control groups in all scenarios, because costs are about 6 to 8 times higher in the deceased than in the non-deceased (cf. ( $>$ Table S3) in the supplement). Since the proportion of de-

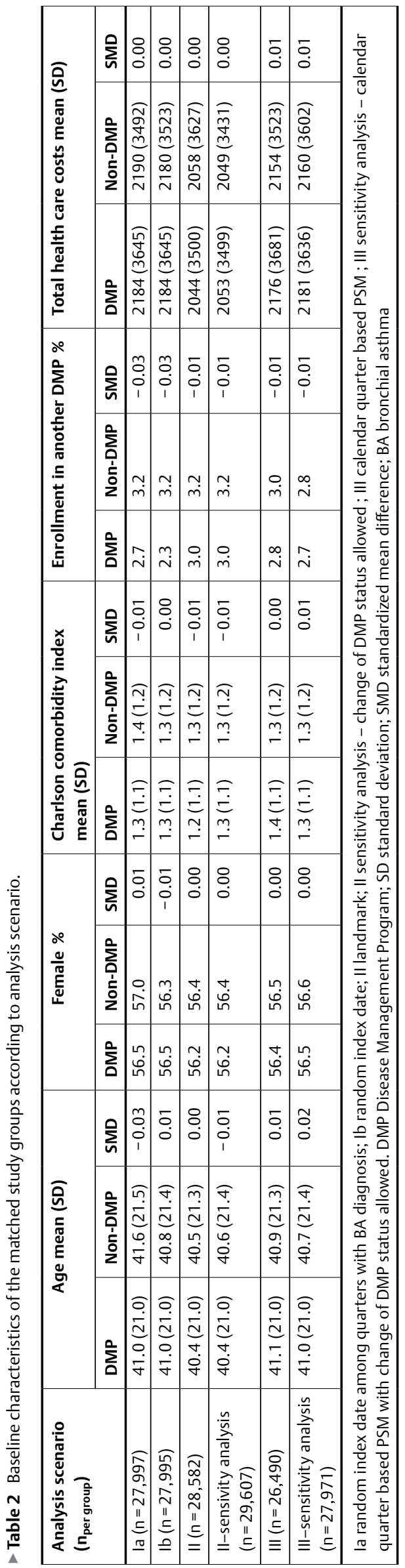


- Table 3 Total one-year health care costs in € and one-year all-cause mortality (\%) in matched cohorts according to analysis scenarios.

\begin{tabular}{|c|c|c|c|c|c|c|}
\hline \multirow[t]{2}{*}{ Analysis scenario (n matched per group) } & \multicolumn{3}{|c|}{ Total one-year health care costs in $€$ mean (SD) } & \multicolumn{3}{|c|}{ One-year all-cause mortality \% } \\
\hline & DMP & Non-DMP & p-value* & DMP & Non-DMP & p-value** \\
\hline $\begin{array}{l}\text { la-random index date among quarters with } \\
\text { BA diagnosis ( } N_{\text {per group }}: 27,993 \text { ) }\end{array}$ & $2659(7477)$ & $2643(6013)$ & 0.772 & 0.31 & 0.99 & $<0.001$ \\
\hline Ib-random index date $\left(\mathrm{N}_{\text {per group }}: 27,995\right)$ & $2659(7477)$ & $2586(5633)$ & 0.188 & 0.31 & 0.53 & $<0.001$ \\
\hline II-landmark ( $\left.\mathrm{N}_{\text {per group }}: 28,582\right)$ & $2636(8770)$ & $2591(6234)$ & 0.480 & 0.28 & 0.61 & $<0.001$ \\
\hline $\begin{array}{l}\text { Il sensitivity analysis-landmark with change of } \\
\left.\text { DMP status ( } N_{\text {per group }}: 29,607\right)\end{array}$ & $2643(8661)$ & 2601 (6979) & 0.516 & 0.28 & 0.61 & $<0.001$ \\
\hline $\begin{array}{l}\text { III-calendar quarter based PSM ( } \mathrm{N}_{\text {per group }}: \\
26,490)\end{array}$ & $2656(7585)$ & $2570(5332)$ & 0.134 & 0.31 & 0.46 & 0.009 \\
\hline $\begin{array}{l}\text { III sensitivity analysis-calendar quarter based } \\
\text { PSM with change of DMP status } \\
\left(\mathrm{N}_{\text {per group }}: 27,971\right)\end{array}$ & $2653(7450)$ & $2563(6035)$ & 0.116 & 0.30 & 0.48 & $<0.001$ \\
\hline
\end{tabular}

ceased patients is low in general and the ratio of costs in deceased compared to non-deceased patients further do not vary substantially between the study groups, the influence of mortality on costs is quite moderate.

To our knowledge, no other studies were published in which mortality was compared between DMP BA participants and nonparticipants. Two large statutory health insurances published one-year mortality rates of DMP BA participants of $0.24 \%(95 \% \mathrm{CI}$ $0.19-0.28 \%)$ and $0.47 \%(0.45-0.50 \%)$, which are comparable to our findings $[14,15]$.

Parts of the differences in mortality can probably be explained by selection effects which claims data do not offer enough information about. Patients who are more likely to have beneficial outcomes of the DMP might be more likely to participate. Previous studies have shown that DMP participants differ with regard to socio-demographic and clinical characteristics from patients not participating $[16,17]$. Covariates were selected to adjust for factors with an impact on total one-year health care costs. Since these covariates might not be sufficient to adjust for factors with an impact on all-cause mortality, a different set of covariates might lead to an improved control of confounding and thus might be considered in future analyses on these or related study questions.

The highest mortality rates were observed in scenario la and II. The especially large difference between DMP BA participants and DMP BA non-participants in scenario la could be caused by the used method to assign an index date to the non-participants. Patients were only assigned index dates in quarters in which they were still alive. In scenario Ib, on the other hand, the random index date was assigned randomly among all possible quarters and patients who died before their assigned random index date in this scenario were excluded thereafter. In detail, from the 401,154 non-DMP participants, 15,137 died between 2013 and 2016. From these patients, 1,482 are excluded in scenario la (index dates which are assigned to quarter of death) while 4,364 are excluded in scenario lb (index dates which are assigned to quarter of death or later). The average time to death for deceased patients is also lower in this group than in scenario lb (704 vs. 766 days after matching).
An advantage of scenario I is the possibility to compare baseline characteristics prior and post matching. For the other scenarios, the cohort of potential controls may contain the same individuals across the index years (scenario II) or index quarters (scenario III) and thus, a unique baseline could not be determined.

A further drawback of the landmark approach (scenario II) is that covariates were assessed in the baseline period prior to the landmark year and the outcomes were assessed in the year following the landmark year. Changes in clinical characteristics within the landmark year are not factored in the calculation of the PS for the risk adjustment. In a post-hoc comparison of characteristics in the baseline period and in the landmark year it became apparent that an adequate balance of these variables cannot necessarily be expected (cf. > Fig. $\mathbf{S 1}$ in the supplement).

The largest number of matched pairs could be analyzed in the sensitivity analysis of scenario II. Scenario III lead to the lowest number of matched pairs, possibly caused by the fact that individuals who enroll in the DMP BA later in the follow up are selected as controls first and can thus not be considered as DMP BA participants anymore. In the sensitivity analysis of scenario III, in which patients could switch from the control status to become a DMP BA participant, the proportion of matched patients was larger and almost equal to scenarios la and Ib.

From a computational perspective, scenario I can be implemented most efficiently since an index date is assigned first and covariates for the PSM can be calculated afterwards. The PSM for scenario II must be carried out in either of 2 ways: (i) covariates for the PSM in each calendar year could be calculated on-the-fly, which enhances computing time for the PSM or (ii) covariates could be calculated for all calendar years in advance, which increases the memory size needed to store the analysis data sets. This problem is even more pronounced in scenario III, as calculations or data storage must be performed on a quarterly basis. We implemented the latter alternative to reduce complexity of the matching as far as possible.

In patient populations in whom the mortality is higher, e.g. in heart failure patients, the impact of the chosen method to select a control on total health care costs might be more pronounced. Studies investigating mortality in participants and non-participants 
of new health services should adequately consider different options to select controls in the absence of an obvious start of follow up. Studies reporting large differences in mortality between DMP participants and non-participants should be interpreted with some caution, as these differences might in part be caused by the underlying method to select controls and their start of follow up which is often insufficiently described [13].

\section{Conclusion}

No significant differences in total one-year health care costs between DMP BA participants and non-participants were observed in any of the scenarios. This could to some extent be explained by the higher mortality in the control groups in all scenarios.

If the loss of potential controls can be compensated, scenario lb is a pragmatic option to select an adequate control group. If that is not the case, scenario III is the more sophisticated approach, with the limitation that baseline characteristics prior to matching cannot be depicted and computational time or memory size needed to conduct the analysis need to be sufficient.

To confirm the performance of the presented methods, it would be worthwhile to implement this study design using a health care service or intervention for which large differences in health care costs have been found.

\section{Conflict of Interest}

None.

\section{References}

[1] Schubert I, Köster I, Küpper-Nybelen J et al. Versorgungsforschung mit GKV-Routinedaten: Nutzungsmöglichkeiten versichertenbezogener Krankenkassendaten für Fragestellungen der Versorgungsforschung. Bundesgesundheitsblatt - Gesundheitsforschung - Gesundheitsschutz 2008; 51: 1095-1105

[2] Schreyögg J, Stargardt T. Gesundheitsökonomische Evaluation auf Grundlage von GKV-Routinedaten. Bundesgesundheitsblatt-Gesundheitsforschung-Gesundheitsschutz 2012; 55: 668-676

[3] Siegel A, Köster I, Maun AR et al. Evaluation einer regionalen integrierten Vollversorgung mit GKV-Routinedaten-Probleme und Herausforderungen. Public Health Forum 2016; 24: 17-21
[4] Kähm K, Laxy M, Schneider U et al. Exploring Different Strategies of Assessing the Economic Impact of Multiple Diabetes-Associated Complications and Their Interactions: A Large Claims-Based Study in Germany. PharmacoEconomics 2018

[5] Andersohn F, Walker J. Characteristics and external validity of the German Health Risk Institute (HRI) Database. Pharmacoepidemiol Drug Saf 2016; 25: 106-109

[6] Schmedt N, Andersohn F, Walker J et al. Sodium-glucose co-transporter- 2 inhibitors and the risk of fractures of the upper or lower limbs in patients with type 2 diabetes: A nested case-control study. Diabetes Obes Metab 2018; 1-9

[7] Rosenbaum PR, Rubin DB. The central role of the propensity score in observational studies for causal effects. Biometrika 1983; 70: 41-55

[8] Rosenbaum PR, Rubin DB. Constructing a Control Group. Using Multivariate Matched Sampling Methods That Incorporate the Propensity Score. Am Stat 1985; 39: 33-38

[9] Rubin DB. Matching to Remove Bias in Observational Studies. Biometrics 1973; 29: 159-183

[10] Austin PC. An Introduction to Propensity Score Methods for Reducing the Effects of Confounding in Observational Studies. Multivar Behav Res 2011; 46: 399-424

[11] Austin PC. Comparing paired vs non-paired statistical methods of analyses when making inferences about absolute risk reductions in propensity-score matched samples. Stat Med 2011; 1292-1301

[12] Nolting HD, Gottberg A, Schiffhorst G et al. Einfluss der Teilnahme am DMP Diabetes mellitus Typ 2 auf die Entwicklung der Leistungsausgaben-Ergebnisse einer retrospektiven kontrollierten Studie auf der Basis von GKV-Routinedaten. Gesundh Ökon Qual Manag 2011; 209-215

[13] Drabik A, Graf C, Büscher G et al. Evaluation der Effektivität eines Disease Management Programms Diabetes Mellitus in der GKV-Erste Ergebnisse und methodische Überlegungen. Z Für Evidenz Fortbild Qual Im Gesundheitswesen 2012; 106: 649-655

[14] Münscher Dr.Christof, Potthoff Frank, Weber Wolfgang et al. Disease-Management-Programm Asthma bronchiale der Techniker Krankenkasse in der Region Nordrhein-Evaluationsbericht zum 31. März 2014. 2014

[15] Münscher Dr.Christof, Potthoff Frank, Weber Wolfgang et al. Disease-Management-Programm Asthma bronchiale der DAK Gesundheit in der Bundesrepublik Deutschland-Evaluationsbericht zum 31. März 2014. 2014

[16] Buntin MB, Jain AK, Mattke $S$ et al. Who Gets Disease Management? J Gen Intern Med 2009; 24: 649-655

[17] Schäfer I, Küver C, Gedrose B et al. Selection effects may account for better outcomes of the German Disease Management Program for type 2 diabetes. BMC Health Serv Res 2010; 10: 351 